\title{
Dethroning the planetary perspective: Dealing with actually-occurring transformations using dialogical sense-making and critical phenomenology
}

\author{
Stephen Woroniecki ${ }^{1}{ }^{*}$, Victoria Wibeck ${ }^{1}$, Kristin Zeiler $^{2}$, Björn-Ola Linnér $^{1}$ \\ ${ }^{1}$ Centre for Climate Science and Policy Research, Environmental Change Unit, Department of \\ Thematic Studies, Linköping University, Sweden. \\ ${ }^{2}$ Technology and Social Change Unit, Department of Thematic Studies, Linköping University, Sweden.
}

\section{Abstract}

Transformation studies lean towards the more practical aspects of change processes and are not yet dealing adequately with their personal and political dimensions. They are arguably constrained in doing so in their current stances, either fixated on systems and how to control them or on individualistic values and behaviours. In this study we show the range of actually-occurring societal transformations that people face can be usefully approached through a combination of dialogical sense-making and critical phenomenology. While distinct, these approaches share a concern with experience and meaning-making, concerns which are often neglected when societal transformation becomes abstracted and alienated from people's lives.

The two approaches reveal how societal transformational change is situated, shared, embodied and laden with diverse meanings. Dialogical sense-making expands the theorisation of the experiential, personal and political dimensions of transformation and shows how the practical dimension of change is always personal and political. Critical phenomenology addresses how the experience of transformation help shape subjectivity, as a lived relation to the world, and sheds light on taken-forgranted, lived norms about bodies and transformative change. Drawing together the three spheres of transformation - the practical, personal, and political - allows a fuller grasp of the complexity in which new worlds may emerge.

Through a discussion of insights from these approaches, we develop a language and framework to understand how people interact with change processes. This development allows new questions about transformative change, based on a reframing of transformations that brings them closer to people's lives. Together these approaches broaden and deepen social-science and humanities contributions to transformation studies and sustainability science.

Keywords: sense making analysis; critical phenomenology; sustainability transformations;

* Corresponding author: Stephen Woroniecki, stephen.woroniecki@liu.se 
Introduction

The literature on sustainability transformations has exploded in recent years in the face of increasing impacts and threats from environmental crises facing humanity. Whilst this explosion represents both a broadening and deepening of the available scholarship on transformation, three patterns can be deduced in the literature that skew the focus of this expanding field.

First, a planetary solutions logic permeates the literature. Indisputably, environmental change expresses itself on a global level, interconnected with its drivers, including consumption and production patterns, that are formed by world economy structures, and demands international cooperation in response. However global-problem-requires-global-solutions-thinking easily becomes universalizing, devoid of context, and instrumentalist (Nightingale et al., 2020). Assuming globally common interests, pathways and courses of action, this perspective seems always to point towards a fixed, unquestionable destination for sustainability transformations (Guha and Martinez-Alier, 1997; Hajer and Fischer 1999; Linnér 2003).

A second predominant and related leaning of sustainability science is its focus on more technical and practical aspects of transformation (Nightingale et al., 2020). Although transformation is a comprehensive concept, referring to fundamental and enduring, non-linear structural change of societal systems that encompasses technological, economic, political, cultural, social as well as environmental processes (Feola 2015; Linnér and Wibeck 2019; Patterson et al 2017), science and policy have especially been preoccupied with managing technological innovations and distribution, and nudging behaviour change in the direction of sustainability (Shove, 2010; Blythe et al., 2018).

A third, less commented skew of the literature has been the emphasis on deliberate transformations (Leventon et al., 2021a). Comparatively fewer studies have focussed on the surprising outcomes of change processes that are not necessarily or universally deliberate or desirable, especially from the perspective of already marginalised social groups (Mehta et al., 2021; Linnér and Wibeck 2019; Schipper et al., 2021).

These skews are understandable, given the applied and solutions-orientated character of the field, and the logical desire to confront unsustainable trends and threats to societies. However, the skews may have unintended effects (Scoones et al., Patterson et al., 2017; Beck et al, 2021). Certain concerns are systematically portrayed as more valuable than others. The particular orientations and values that co-develop in transformation scholarship shape the character of the field, establish an $a$ priori ontology and epistemological assumptions that prefigure the analysis, and privilege questions of outcome at the expense of questions about process or the conditions of experience (Nightingale, et al., 2020; West et al., 2020). This has concrete consequences for pathways of transformation (Priebe et al., 2021).

The present study begins from an acknowledgement that the current preoccupation with creating research for transformation may be missing whole classes of transformative change and whole constituencies of people in transformation studies (Moore et al., 2021). It may also miss the chance to explore how experiences of environmental change can be both epistemically and personally transformative (Benessaiah and Eakin, 2021; Jones, 2018; Nicholas, 2021; O’Brien, 2021). These 
neglected aspects may translate into impoverished theories about transformative change and the conditions in which it arises. The dilemmas and complexities of intent and desirability that are central to transformations have been tackled only in a limited way (Manuel-Navarrete and Pelling, 2015). Perhaps most surprisingly, transformation continues to be largely taken for granted as positive and desirable (Patterson et al., 2017). There is a gap in addressing negative or involuntary aspects of societal transformations and appreciating the implications of social difference and power relations. This leads to neglect of important phenomena, such as resistance (Johansson and Vinthagen, 2016; Woroniecki et al., 2019).

The question of how people shape and are shaped by transformative change needs deeper and broader attention (Stålhammar, 2020). Where we focus on people, we emphasise human beings as subjects, critically enmeshed in relations with others, and as always situated selves - which diverges from an individualistic lens, which locates people as apart from society as separate entities.

Other researchers have made important inroads into addressing these gaps and in the process contributed interesting new avenues for transformations enquiry. In transformations research there have been important steps to understanding the ways that people are at the head and heart of change processes, drawing on the personal and organisational change literature (Westley et al., 2013; Wamsler et al., 2021; O'Brien 2021). Particularly the work by Karen O'Brien and Linda Sygna (O'Brien and Sygna 2013; O'Brien 2018) emphasizes the personal and political dimensions of transformation. ${ }^{2}$ They outline three interacting 'spheres' in which transformations occur: the practical, the political and the personal sphere. While the practical sphere encompasses e.g., sociotechnical innovations, managerial reforms, and lifestyle changes, the political sphere focusses on governance (especially formal and informal institutions), and other reified social forms of collectives and movements. The personal sphere focusses e.g., on subjectivity, values, beliefs, discourses, and paradigms. In addition to O'Brien's and Sygna's focus on 'individual and collective beliefs, values and worldviews' (2013: 5), we argue that the personal sphere is also where lived experience of health, well-being, insecurity, risk, loss and damage take centre-stage.

In addition, there has been a turn towards the power of storytelling, imagination, and narratives within change processes (Milkoreit 2017; O'Brien et al 2019; Veland et al 2019; Behagel and Mert, 2021; Stripple et al., 2021; Uhrqvist et al., 2021; Riedy 2021). Also, recent research focuses on the notion of transformative experience and 'inner transformations'; sometimes with a focus on events and happenings that occur in an individual's life that change their values and priorities towards more sustainable attitudes (Stålhammar, 2021; Wamsler et al., 2021) in ways that are attentive to the content of these attitudes. In contrast to the focus on the practical sphere of transformation, these new avenues in transformation research emphasise the power of thinking differently.

Despite these important contributions to developing the personal sphere, some key questions remain. It is still not clear how to hold together the personal, political and practical dimensions of transformation in a coherent way (Cook et al., 2016). What is also neglected are philosophical studies of the structures of experience, one's embodiment, and the role of time, relations to other beings, and the world that one lives, for experiences of transformations and subjectivity. In other 
areas than environmental change - such as in phenomenological studies of illness experience or transformative experiences during the Covid-19 pandemic, research has explored how transformation is experienced, from within that experience (Leder 1990; Carel et al 2020). This leads to interesting new opportunities to expand what transformative experience can mean for people as situated, singular selves, i.e. as unique and different and always situated in relations to others and in a world, and as formed in and through these relations - in contrast to individualistic understandings of the self as self-sufficient and neatly set apart from others and the world.

The overarching aim of this article is to go beyond a monolithic idea of what transformation is, where it leads, and how it relates to its context by contributing to a framework for the study of actually-occurring transformations. These are the myriad processes of transformative change that are already happening across the world, simultaneously and often in concert. They involve a diversity of experiences, that may be comparatively positive and negative, both deliberate and nonvoluntary, as well as producing winners and losers (Patterson et al., 2017).

Deepening and broadening out our ideas of transformation calls for new approaches that can deal with the implications of this shift. Our starting point is inspired by John Barry's (2012) argument for paying more attention to "actually-existing unsustainability" before embarking on the journey towards sustainable solutions. For Barry, the phrase 'actually-existing' denotes a prioritisation of the kinds of change that people face in their day to day lives. These may relate to co-evolving environmental changes, economic and cultural changes, and societal or policy responses to threats and risks. In this way, the term resonates with recent contributions of social research on climate change (Ensor and Hoddy; 2021; Mehta et al., 2021; Mehta and Harcourt; 2021; Schipper et al., 2021; Quealy and Yates, 2021).

Specifically, we introduce two different theoretical perspectives: that of dialogical sense-making and critical phenomenology that can contribute significantly to this shift. As we will show, the dialogical approach to sense-making analysis provides tools for dealing with meaning-making and differentiated experience coherently across all kinds of actually-occurring transformations and enables researchers to address the processual and relational character of transformation in detail and depth (West et al., 2020). Meanwhile, the critical branch of phenomenology engages with lived experience and attends to structures that "play a constitutive role in shaping the meaning and manner of our experience" (Guenther 2020:12). It engages with our very ways of seeing, questions the taken-for-grantedness of experience (thereby allowing transformation of the understanding of that experience), and - when so doing - may challenge assumptions about human being especially in the context of power relations (cf. Weiss et al 2020)). This combined contribution can honour the potential that Linnér and Wibeck (2019) see for transformation studies in unleashing "new ways of making sense of the predicaments of our time and the inevitable shifts we are making" (p5).

Bringing the dialogical sense-making and critical phenomenology approaches into dialogue with each other, we introduce three transformative movements; re-location, re-orientation and pluralisation, in order to situate the researcher and research act more appropriately in relation to actuallyoccurring transformations. The structure of our enquiry is as follows. We will start by laying out three observations about transformative change from our reading of the current state of the field. We will discuss what it means to see transformative change beyond a systems ontology and 
planetary perspective. We will then introduce dialogical sense-making and critical phenomenology, after which we will discuss how these approaches can contribute, in different ways, to a specific case of actually-occurring transformation.

Three Observations

We start by laying out three observations about the state of transformations studies within sustainability science. Together these represent differences between the focus and normative orientation of transformations research compared to the kinds of transformations that are actuallyoccurring in people's lives.

- Observation 1: Transformation research commonly attempts to transform systems towards planetary sustainability.

A dominant emphasis in transformations literature in recent years has been on learning how to deliberately transform systems towards sustainability and use this knowledge to intervene in systems in order to incite transformative (non-linear) change (Leventon et al., 2021a). This is what some scholars refer to as solutions-oriented research or transformative research - that is, research for transformations - in contrast to the more limited strand on descriptive-analytical transformation research, or research on transformations (Feola 2015; WGBU, 2011). In research for transformations, attention has for instance been focused on locating "positive tipping points" or identifying system leverage points (Abson et al., 2017; Leventon et al., 2021a). The outcome (i.e., a desirable system state) has been set-out a priori to the investigation: "societal transformation towards sustainability" (Linnér and Wibeck, p3), though it is rarely clear what sustainability or transformation entails and for whom (Scoones et al., 2015; Pathways Network, 2021).

The global-problem requires global-solutions thinking on show here compels abstraction and objectification, distance and alienation as though they were inevitable aspects of transformation. Normative aspects are made implicit and the research act becomes a search for apparently neutral facts (such as 'science-based targets'). There is a shedding of the value propositions of a given situation, in favour of fighting for a singular value proposition assumed to be held by all (universalizing sustainability).

In research for transformations researchers align themselves with the change process, locating themselves in or besides the transformation as agents of change (Beck et al., 2021). In effect, this entails sketching an implicit persona that stands at the levers of control, in what has been referred to as 'cockpitism' (Hajer et al., 2015). The combination of the researcher and the system directed towards transformation involves a series of movements into abstract space. This effect is clear in references to earth system governance or stewardship of planetary boundaries. One may see the movement as a deliberate process of dis-location, reflecting natural science's historical antipathy and distrust of the human condition. It involves a drawing away from the particular situation of the researcher (e.g., the desk, chair, computer etc), to envision a mental model, a set of abstractions and reductions, using techniques such as maps, models and satellite data, or other modes of similarly abstract sight (Haraway, 1998). Science for transformation can be seen as a specific variant of the standard scientific orientation of detached observation, described by Jasanoff as "the process of 
making things impersonal [that] eliminates not only subjectivity but also meaning" within the act of research (Jasanoff, 2010, p234).

This is a scaling process in which ontological, epistemological, and normative work is accomplished in the name of instigating and controlling transformation (Forsyth, 2021; Lahsen and Turnhout, 2021;) In constructing this planetary perspective on transformation there is an impoverishment of the various senses, and in particular the sense of being there. The diminishment of reflexivity; the awareness of having a perspective, hides the actors involved in the research act, the prefiguring power of the research techniques and their situatedness in particular conditions. The deliberate drawing away from human conditions of experience of transformation towards the planetary perspective privileges higher scales of change, and particular kinds of policy and governance. These diminished forms of imagining transformation are co-produced with particular forms of governance and thus have concrete implications besides their epistemic consequences (Castree, 2021; Forsyth; 2021).

- Observation 2: Many kinds of transformative change are undesirable or involuntary.

The movements into abstract space are seen as necessary responses to the gravity, depth and breadth of the threats. However, when environmental problems are abstracted to the level of climate change and biodiversity loss, for instance, or further abstracted into planetary boundaries and system tipping points, they lose their local, essential and phenomenal qualities (Jasanoff, 2010) and how they matter to people (O Brien, 2021).

Whilst sustainability transformations are seen as desirable, intended shifts in the world-system, environmental threats and trends are the undercurrent of a planet transforming in response to human activity. These threats and trends represent undesirable, involuntary transformations. Both these kinds of transformations are made sense of through the frames of intent and desirability. Though these frames can both be located as part of people's everyday lived experience, how people experience and make sense of intent and desirability is often lost or simply assumed in the movement into abstract systems science and governance.

This comes at a price, given that locating these frames in people's lives would allow analysis of transformative change to be grounded in experience and meaning. It discounts the possibility of asking what people go through when the world changes, sometimes, catastrophically, and how this affects them as situated selves, including their politics, relations and practices (Braun and Whatmore, 2010; Manuel-Navarrette and Pelling, 2015; Castree, 2021).

Profound environmental changes are also often understood on abstract and large-scale terms . Global problems are seen as the most concerning and existential; species extinction and climate change occupy more imaginative space than air, water or soil pollution. Earth systems science has led the way in making sense of such processes, at scales beyond those that can be sensed by a single human being (Morton 2013; Edwards, 2021). Undesirable transformative changes are commonly imagined within the schema of the earth system (Latour, 2018). The language tends towards the language of systems; thresholds, regime shifts, tipping points, planetary boundaries, extinction (Herrfahrdt-Pähle et al., 2020; Ensor and Hoddy, 2021, Mehta and Harcourt, 2021; ) as though 
unintended and undesirable transformations should naturally be studied through systems science and its related techniques. The temporalities associated with such ontologies are those of countdowns and the fast-approaching environmental 'event horizons' (Moser, 2020; McHugh et al., 2021; Patterson et al., 2021). This creates an epistemic feedback loop or closure, fuelling 'cockpitism' and breeding urgency in governance responses, which can close down on potential alternative ways of imagining transformation (Castree, 2021; Priebe et al., 2021). Despite the systems language urgency is still a feature of relational time, which like desirability and intent, is located within people's lives. It is thus an example of how scientists are situated selves, not detached observers, but still try to maintain a detached style in their analysis.

What we call environmental shocks with the power to transform human lives may arise 'all at once' and completely overwhelm the senses, as in the case of fire or flood, but even in such extreme cases they are not experienced as 'thresholds or tipping points' (Nicholas, 2021). They are also phenomenal, affecting our bodies and those around us. They awaken our senses, demand our attention and care, and shift the ways we think and relate to each other (Jones, 2018). Actuallyoccurring transformations have qualities that are familiar to us, changing our sense of ourselves in relation to our environments, provoking feelings of vulnerability, danger, loss, anger, anticipation and concern (Armiero and de Rosa, 2017). This makes them, amongst other things, quintessential transformative experiences. Further, we suggest that such experiences cannot be understood as set apart from pre-existing worlding practices, narratives and stories, but instead should be understood as imbued with belonging, history, and memory, as well as creativity and potentiality, and often marked by power relations (c.f. Gelves-Gómez and Brincat, 2021; Jackson, 2021).

- Observation 3: Even deliberate transformations are experienced differentially by actors with different standpoints

Various configurations of desirability and intent are possible even in the same transformative change process, and different transformations are experienced and made sense of in particular ways depending on a person's standpoint (Hoque et al., 2018; Nightingale et al., 2021). This denies the possibility of a priori categorizations of change, framed as intended or unintended, desirable or undesirable. When no transformation is simply voluntary or involuntary, desirable or undesirable, new obligations are created, shifting the epistemic and normative orientation of the researcher towards the process itself and the ways that different people are bound up with the change process. Paying attention to the process opens it up to new kinds of enquiry, such as how it invokes, transmits, challenges, or reifies social differences.

This openness allows transformative processes to be questioned differently: intended and desirable for whom? No single transformation is objectively desirably or undesirable in its entirety, no matter the aggregate or utilitarian effect. Nor can any transformation be seen as uniformly intended or unintended. Transformative change escapes the capacity of science to know conclusively about the outcomes of a particular intervention. Likewise, no societal transformation is definitively intentional, being instead inherently contingent (Olsson et al., 2006). Furthermore, what looks both desirable and intentional from the standpoint of one person (the captain in the cockpit) may look very different from those with different standpoints. This complicates the notion of an objectivelydesirable transformation, without reducing these processes to relativism or simply a matter of 
different perceptions (de La Candena and Blaser, 2018). Research shows us that the ways that people relate to change processes often depends on their footings within relations of power (Kaijser and Kronsell, 2014; Nightingale, 2017).

This matters especially in a world where transformative changes are not universally accepted, and consensus positions on change are rare and not necessarily even desirable (Mehleb, 2021; Schipper et al., 2021). Many if not most transformations are not deterministic movements from $A$ to $B$, but rather emerge from the politically charged interactions between actors enmeshed within complex socio-ecological configurations, and their outcomes are contingent and dialectical (Pelling et al., 2015; Eriksen et al., 2015). It is inevitable that some people will experience those as involuntary or undesirable.

In these situations, the abstract biophysical criteria that are often used to frame sustainability transformations, such as planetary boundaries and negative tipping points, can represent complexity blinders (Priebe et al., 2021). When transformative change processes are studied in hindsight, and people are asked what motivated their efforts, such abstract biophysical criteria may not be cited. Instead, people's priorities may lie in more proximate concerns about risks, safety, desire, and the reliability and accountability of those entrusted with governance responsibilities (Ensor et al., 2019). Just as transformations are inherently uncertain, they may also involve different forms of loss. These are dimensions of transformations that are not amenable to the abstraction and reduction to quantitative, technical criteria of the planetary perspective.

This section summarised three observations that show the difference between the current dominant planetary perspective to transformation studies and the ways that are people are central to change processes. Once we start to relocate analysis, we can see that many, if not most, kinds of transformative change are contingent processes, where elements may be intended or unintended, and some elements desirable for some but not for others. Thus, it becomes clearer that whollydirected, wholly-desirable transformations are a diminished form of analysis that cannot properly account for what is most important to people living through and experiencing times of transformative change. We now turn to dialogical sense-making and critical phenomenology as approaches that are well positioned to offer a complementary analysis. After describing these approaches and setting out some of their similarities and tensions we will then show their advantages. This will demand a reinterpretation of transformation in some important ways, which will make some demands on future transformations that acknowledges these predicaments.

\section{Dialogical Sense-Making}

Dialogical sense-making offers an understanding of interaction and its cultural contexts (Wibeck and Linnér, 2021). Dialogism is an epistemological framework that is concerned with how people gain knowledge about and attribute meaning to the world, and with the roles of cognition, communication, and action in sense-making (Linell, 2009). Starting from the assumption that "our being in the world is thoroughly interdependent with the existence of others" (Linell, 2004: 5), dialogism emphasises the context-dependency of sense-making, taking into account both situated interactions and socio-historical backgrounds. As such, sense-making has a strong cultural schema, 
being dependent upon reference points that may not be arrived at directly through one's own direct and singular experience, but rather gained through social life.

Dialogism homes in on social interaction for the formation of identity and subjectivity (Voloshinov, 1930) and even talks about the "dialogical self", which is "contextually interdependent with others and with contexts, moving between different positionings but still part of continuities" (Linell, 2009:113). This "other-orientation" shapes sense-making, in interaction with others and with the surrounding world (Bakhtin, 1986; Linell, 2009; Marková et al., 2007). Dialogical sense-making in particular analyses how the processes of ascribing meaning to the world are produced not by individuals thinking and acting alone but rather through interactions and dialogues, both directly with other people in a particular interaction but also as part of broader public discourse and in interaction with different ideas, arguments and standpoints (Marková et al., 2007).

The basic principles of dialogism - including relationism and the emphasis on situated as well as socio-historic contexts, and interactions - have been translated into a framework for dialogical sense-making analysis (Wibeck and Linnér, 2021) that could help shed light on how people experience and make sense of actually-occurring transformations. The goal of dialogical sensemaking is to try to understand the content of communications and analyse the communicative processes through which meaning-making occur. It is thus designed to capture both content and process, i.e., enabling broad explorations of standpoints, understandings, and social representations, while also supporting in-depth analysis of how linguistic or other meaning-making resources are used in communication.

A dialogical approach to sense-making acknowledges both intersubjectivity and common ground, and the asymmetries, tensions, and conflicting perspectives that may be expressed and experienced in communication (Linell, 2004; Marková, 2003). Dialogical sense-making therefore seeks to explore commonalities as well as varieties or conflicts in sense-making in different contexts and among different groups of actors.

Dialogical sense-making allows us to analyse the narratives, metaphors, stories, frames, and values that comprise particular discourses. Each of these has its own methods and approaches, though they can be brought together under the umbrella of dialogical sense-making analysis. Such analysis has recently been applied in a sustainability setting by Linnér and Wibeck (2019; see also Wibeck and Linnér, 2021 and Wibeck et al., 2022). A feature of this analysis is the approach of analysing both vertical sense-making, one data set at a time, and horizontal sense-making, across different sets of data. This allows for a treatment of scales of sense-making.

\section{Critical Phenomenology}

Phenomenological philosophy studies subjectivity and lived experience from a first-person perspective, and subjectivity, or the self, is understood as embodied and situated in relations with others in a world. Further, phenomenologists share an interest in how the world is experienced and constituted in term of meaning - how the world or objects in it appear to the self that is directed to these - and a shared "methodological commitments" is the "refusal to accept the taken for grantedness of experience" (Weiss et al 2020: xiii). This has led to studies of lived experiences with 
the aim of making explicit, clarifying, and better understanding aspects of experience that are so deeply rooted in our lives that we often take them for granted, with an eye for structures of meaning that help shape experience (see, for example, Malmqvist and Zeiler, 2010). When explored phenomenologically, mundane features of experience can disclose and help us understand central aspects of human existence. ${ }^{3}$ Further, phenomenological philosophy has branched out into a rich set of sub strands that include e.g., feminist, queer, and critical race approaches in phenomenology. Recently, critical phenomenology has been used as an umbrella term for these sub strands (Weiss et al 2020).

We take three foci from phenomenological philosophy including critical phenomenology. First, we acknowledge a focus on situated subjectivity in the production of knowledge. In line with the understanding of subjectivity as embodied and a relation to the world, phenomenologists have examined constitutive conditions of the production of knowledge from within the experience of the self who engages in knowledge production. A phenomenological insight, here, is that steps taken to seek to extract oneself from everyday human experience in order to create a natural science position to the world (a stepping back and away from the world in order to 'observe' it and develop appropriate concepts to represent its functioning) miss out much if taken to mean that knowledge production does not always already rest on the existential conditions of human being in the world. Concretizing implications of this insight, phenomenologists have studied how subjects make use of different frameworks or methodological tools in order to constitute different kinds of knowledges, how distinct methodologies allow for varying ways of "world-making" while underlining how the practice of producing knowledge always is grounded in the lived everyday world of sense and meaning of the situated self engaging in this activity (c.f. Islami and Wiltsche, 2020).

Second, we see phenomenological investigations of embodiment and perception as promising for transformation studies. Phenomenological philosophy has offered a departure from previous dualistic understandings of for example mind and body. This is the case, for example, in Maurice Merleau-Ponty's description of the self as neither existing only as consciousness nor as a thing, and the lived body as a lived relation to a world immersed in meaning, opened up to me through my bodily senses (2013). Feminist and other critical phenomenologists have added to this reasoning, and examined the role of the singular body of a particular age, with a particular sex, race, ethnicity, and sensory-motor capacities for subjectivity and perception (e.g. Alcoff, 1999; Weiss, 1999; Diprose, 2002; Shildrick, 2002; Young, 2005; Zeiler and Käll, 2014; Al-Saji, 2014).

The understanding of embodiment as a lived relation to the world is central to phenomenological conceptualisations of perception. Phenomenologically, perception is understood in terms of intentionality (as a directedness) and as a relation between the person seeing and that which this person sees: what the seer sees depends on what stands out as foreground and what becomes background for this person, and what we perceive is interwoven with our way of engaging with the world and informed by our bodily possibilities and perceptual and motor habits. In this way, as formulated by Merleau-Ponty and elaborated by c.f. Asia Al-Saji (2014), we do not simply record

\footnotetext{
${ }^{3}$ Phenomenologists have therefore explored basic structures of experience such as temporality (for example, how does the experience of time help constitute one's sense of self and help shape remembering?) or embodiment (for example, how does the bodily self's sensory-motor relation to its world help constitute the world of meaning?).
} 
what passes by the retinal field, but "learn to see". Al-Saji quotes Merleau-Ponty's description of how "[t]he gaze gets more or less from things according to the way in which it questions them, ranges over or dwells on them. To learn to see colors is to acquire a certain style of seeing, a new use of one's own body," and she adds that in learning to see, it is "not only the body that is recast by habit, the perceived world is differentiated and configured in new ways; it appears differently" (2009: 377). Of relevance for transformation studies, we suggest, is a critical phenomenology take on perception, that is attentive to how socio-political, historical, and epistemological structures of privilege can normalise and naturalise certain ways of seeing. We then underline the need to critically examine "the patterns according to which we see" as well as what we see (Guenther, 2020: 16). Further, depending on how the bodily self is dynamically oriented in the world, and how the world is opened up to the self through perceptual and motor habits (which do not imply any determinism), some routes of actions or choices or objects may be perceived and experienced as for the self, more so than others (see also Zeiler, 2018).

Third, we see a phenomenological focus on transformative experiences as particularly appropriate for the field of transformation studies. Phenomenological philosophy is apt to explore the structures and content of epistemically and personally transformative experiences, i.e., experiences that provide "forms or degrees of knowledge and understanding that were previously unavailable and, more importantly, previously inaccessible, insofar as they depend on having the relevant experience" and experiences that "fundamentally changing one's values, preferences, desires, and, therefore, transforming one's identity in substantive ways" (Carel and Kidd, 2020: 119). As before, the phenomenological focus would be on what it feels like and means to experience such changes, for the self as embodied and situated in a socio-cultural and historical world. Phenomenological inquiry would not simply acknowledge that disruption of one's previous routines can make possible reflection on how to live (i.e., a general insight in much discussion of disruptive changes), but could ask what such experience of transformation means for the embodied self that lives the transformation, for the constitution of meaning. Questions to ask could be how transformative experience can shape and generate the self's sense of self, as bodily and situated, and how her possibly changed sense of self in turn can inform her experience of the world. A critical phenomenology inquiry could ask about the experience of undergoing transformation and developing new knowledge through it - with an eye for the constitutive role of historical and social structures "in shaping the meaning and manner" of this experience (Guenther, 2020: 12).

\section{Bringing the approaches into dialogue}

To illustrate the differences that dialogical sense-making and critical phenomenology provide, we sketch a particular and prescient case of involuntary transformations to Pacific Island States and communities caused by climate change (Box 1 ). We pay special attention to the ways that people experience and make sense of these changes, including the loss at stake, and the actions that people may take in response. 
Box 1 Illustrating Involuntary Transformation in the Pacific Islands

Pacific peoples have intimate relationships with the places and the communities they live in, developed over many generations, and expressed in language, customs and religious beliefs. People rely heavily on the land, the coast and on the ocean. All these elements are part of who people are.

Across the Pacific Islands, people are used to coping with uncertainty and dramatic weather, and dealing with the specific challenges presented by the landscape, community, and country they live in. However, this is a part of the world that is changing faster in response to climate change than others. Recent changes are overwhelming people's capacity to respond and adapt, leading to different kinds of losses and damage. Storms may be now so powerful that they destroy infrastructure and leave economic activity almost at a standstill. Though recovery from one storm may take years, the frequency of storms has also increased, so that recovery may not be completed before a new event takes place. These impacts may affect different groups to different extents, depending on the cultural norms and roles often afforded to different groups (such as who fetches water and fuel for cooking). More extreme rainfall events and storms cause flooding, damage property, ruin crops and kill livestock. These events affect individuals, households and communities in different ways. Heritage, history and homes may be lost. People may have to leave their homes, leaving behind everything that they know and much of what they value. Some refuse to go, despite the risks of staying. These are places people feel they belong to, and their identities and ways of life are bound up there. The losses are deeply felt and irreplaceable. There may be no going back. People who do not move may experience a sense of disorientation, as the place they thought they know is now no longer the same. For example some species of wildlife may no longer exist. The permanent loss of a cherished visiting place or sacred site to rising sea levels and coastal erosion can never be accounted for in monetary terms. People who do move may be faced with strange and unfamiliar situations, where they cannot continue their livelihoods. They may have insecure land tenure, or face tensions with people who already live there. These transformations are caused by climate change, the responsibility for which does not lie with the people who experience these events. Despite negligible responsibility, people in the Global South are far more likely to lose their lives in climate-related disasters. Activists and social movements can raise recognition of these stories and bring them to different audiences, raising the awareness about the impacts. Solutions are available, but the resources may be lacking.

Source material: Habu, G., 2021; Habu., G., and Yeo, S., 2021, IIED, 2021

Dialogical sense-making is concerned with socially-shared knowledge and with how meanings are shaped in interaction between participants in spoken or written exchanges, between different ideas and arguments and in relation to different societal discourses (Marková et al 2007). A sense-making analysis would for instance focus on commonalities and variations in how different actor groups in Pacific Island States understand the causes and effects of, as well as preferred responses to, climate change, asking for instance how research participants make sense of climate change in terms of root causes, the problems to be solved, and goals and measures of climate action. It would analyse where participants agree, where they disagree and how meanings are negotiated. It could also systematically explore individual and societal narratives of experiences of living in communities that are faced with the threats of climate change. 
Beyond a mere focus on the content of sense-making, it would also be relevant to pay attention to sense-making processes, by exploring, for instance, how the use of linguistic resources such as metaphors, key phrases, analogies or distinctions contribute to the shaping of meanings. A particular focus could be on scrutinizing how experiences of climate-induced threats and losses are interpreted in analogy with, or in contrast to, historical experiences. Moreover, other ways of shaping and expressing meanings, such as through artistic expressions, could also be a focus of analysis.

Paying attention to how interests can be underpinned by certain sense-making contributes to understanding power asymmetries and inequalities in framing climate-related discourses and identifying what perspectives and whose voices are marginalised. Methodologically, sense-making analyses in the context of Pacific Island States would need to be attentive to the dialogical practices that are relevant to the communities participating in the research. For instance, this could mean applying a Talanoa-inspired conversational methodology (Vaioleti, 2006) rather than interviews or focus groups.

As seen above, phenomenological philosophy is concerned with subjectivity and the structure and content of lived experience. While dialogical sense-making could focus on commonalities and variations in how different actor groups in Pacific Island States understand causes and effects and different responses to climate change, phenomenological inquiry could address not only the content of lived experiences of climate change but also our very ways of perceiving climate change, i.e. it could attend to the patterns according to or through which we, as singular selves, see.

Phenomenology could listen and engage with results from studies from within dialogical sensemaking or other qualitative research that engage with narrated lived experiences by people living in the pacific or elsewhere, with different experiences of climate change. However, phenomenology inquiry would then ask, e.g., how the changing world is constituted for the singular self through distinct forms of production of knowledge and meaning-making, and how the situatedness of the self constitutes a condition for what knowledge is produced. It could ask how people make use of different frameworks, with a focus on how the frameworks (or methods and normative dimensions of them) allow varying ways of seeing and making sense of the world, thereby contributing to discussions of how to understand people's different perceptions and lived understandings of climate change.

Further, phenomenological philosophy could ask how transformative experience shape the self's sense of self and agency when living with loss or potential loss due to climate change, how climate change appear to the self in such experience, and how the self's sense of self can be constituted through transformative experience. To such questions, critical phenomenology could add questions of how structures of power help shape the ways people perceive and experience climate changes, including how they help shape the meaning of climate change for selves that are differently positioned in relation to them. To return to the focus on perception: critical phenomenology could also examine the constitutive conditions of perception, starting in the phenomenological understanding of perception as a directedness that orients us in the world and in relation to others, and as interwoven with our very ways of engaging with the world. It could ask how sedimented norms about spaces and bodies can shape the perception and understanding of risks and losses that climate change can entail, as well as the need for urgent action. Methodologically, this would be a 
philosophical inquiry, though one that engages with insights from historical and social sciences works (see, for example, Guenther, 2013; Zeiler and DeBoer 2020).

Using sense-making and critical phenomenology does not deflect attention from power relations or socio-economic structures. On the contrary, we acknowledge their role for actual-occurring transformations (Woroniecki et al., 2019), and we argue that these approaches are important means to understand how structures are formed and maintained. We see structures, whether defined as the rules and resources that influence what actions people can take (Pettit 1993; Wendt 2015) or the ways that our very being and perception is directed and condition, as reproduced through our daily practices, If the practices and lived experience change, so do the ways in which the structures are reproduced (Lippuner and Werlen 2009), what Anthony Giddens (1984) refers to as the duality of structure.

Discussion

Setting out these approaches and then contrasting and comparing to one another through reference to a common illustration of actually-occurring transformations allows us to see how they make particular contributions that are not honoured by synthesising the two approaches. Instead, we seek to illustrate their complementarities in advancing a means through which to understand transformations from people's own perspectives as situated selves, how those transformations shape their ways of seeing and being in the world, and how this is made sense of dialogically.

We have shown how this departs from dominant modes of seeing transformations. We have demonstrated the kinds of questions presented by the two approaches can be used to advance our recognition of transformative processes as complex and contingent. These are open frameworks, allowing culturally-specific frames and world-making practices to be centred as part of analysis, rather than prescribing interpretative frameworks a priori to the analysis.

The previous section demonstrated how we can ask different kinds of questions from combinations of these approaches in different contexts. Similar to people's dialogic sense-making and phenomenological accounts of loss and transformation in the Pacific we could use these approaches to understand diverse kinds of actually-occurring transformations, such as mega-fires, large-scale adaptation infrastructure, forced relocation, or green policy, and how they translate into people's experience and ways of making sense of themselves.

Learning from people going through these experiences and changing relations and sense-of-self can further build the social science contribution to transformation studies, enabling better transformations practice and policy (Masarella et al., 2021). The experience of worrying about keeping the heating on during the winter without fuel allowance for example, may shape the way people interpret and respond to these policy prescriptions, and - also - their sense of self and agency. We can use the combined approach to question how policy prescriptions for transformation, such as cutting energy subsidies, will impact on people's lives and ways of being in the world (Haverkamp, 2021). By asking how people make sense of changes, we can better account for unexpected changes and unexpected responses. 
We see this combined approach as a useful counterpart to a systems ontology, which tend to position those elements as superficial rather than fundamental aspects of systems (de la Candena and Blaser, 2018). Everyone are participants in shaping the dialogical totality that is a transforming world, which whether intended or unintended, makes demands of people and their ways of being in the world. We might use dialogical sense-making to understand why things matter to people and thus why things become politicised in certain ways that may not be amenable to prediction from the planetary perspective or from analysis of individuals values, choices or behaviours, and critical phenomenology to understand how experiences of transformation and political - and politicised decisions can feed into and help shape subjectivity and perception.

The combined approach offers a way to engage with the three spheres model of transformation (O'Brien and Sygna, 2013; O'Brien, 2018). They allow us windows into in the liminal spaces and precarious living arrangements that represent real evocations of the personal, political and practical spheres that are not available to us if we do not take account of people's differential experience and people's own ways of making sense of their changing worlds (Haverkamp, 2021). They allow a critical attention to taken-for-granted dimensions of lived experience.

Re-location, re-orientations and pluralisation; new modes of thinking and being in a changing world

We set out here the key contributions of these approaches to thinking and living in a changing world where transformations are demanded of us as human beings and experienced as an ongoing, evolving process (Berzonsky and Moser, 2017; Tsing 2017; Kaijser and Lövbrand, 2019). This has implications for both how we do research in such a world, and also how we interpret what transformations are.

Relocation

We have argued that dialogical sense-making and critical phenomenology are helpful in bringing transformation processes to where they are tangible and percieve-able, and part of ongoing lived experience. The approaches allow a return to how transformative changes are made sense of, experienced, and storied, within the shared unfolding of people's lives (Ensor et al., 2019; Quealy and Yates, 2021), and this not only in an empirical way - but in ways that allow for the combination of empirical and philosophical inquiry.

Re-locating people as central to change processes involves establishing transformation as something that plays out between people, requiring us to move from figurative to literal sight, into the phenomenal in its fullest, embodied, and most relational sense and using techniques that can grapple with how people make sense of what is happening to them and the world they feel changing.

Re-locating the analysis can be used to make sense of involuntary transformations, such as those associated with climate extremes, such as heat, drought, fire, storms and sea level rise. These are reinterpreted not as far away concepts or objects as they are often visualised in climate science but enter into worlds of being through histories of specific actions, processes and above all (differentiated) subjectivities. 
This movement also helps to understand more deliberate transformations towards sustainability. The destination of travel of transformations 'towards sustainability' is far from certain, especially given the possibility of differential wins and losses for different groups as well as the variety of standpoints that different people occupy (Blythe et al., 2018; Stripple and Bulkeley, 2019). This goes quite some way beyond the limitations imposed by systems-based approaches, where the 'subjective' is often superficially located on the surface of otherwise very structural, depersonified and objectified accounts of change (Braun and Whatmore, 2010; O'Brien, 2017).

Locating actually-occurring transformations means recognising how transformative change is expressed in changing situations, including the changing situatedness of particular selves, and in changing relations, including relations of power. Transformations can be felt, expressed and grappled with. They are ongoing intersubjective processes, constantly challenged, shaped, negotiated by particular people, who are likewise changed by them.

Locating transformation introduces possibilities to dig deeper into actually-occurring transformations as inter-subjective processes playing out between situated selves that are themselves changing (Moriggi et al., 2020). Accounting for people's changing subjectivities in these processes might mean greater attention to diverse, embodied and meaning-laden experiences of change, including shifts in the frames of desirability and intent. It might mean exploring the firsthand accounts of people's evolving responses and actions vis a vis reified social structures in pathways of collective action and resistance. It could go deeper into the (changing) structures of perception that lie behind these more tangible changes.

\section{Re-orientation}

People shape change and are also shaped by it. In a sense, they are directed by it, and in so doing take on new orientations. This involves the constitution of the self with the other and with the world This relational re-drawing of the world may entail new transformations storylines, or the closure of older storylines that no longer seem relevant.

Such realisations are in marked contrast to the detached observation of abstract systems or structures framed as out of reach of people, disconnected from their lives, and liable to change only through the governance techniques of cockpitism and mechanistic leverage points.

Drawing transformation and its constituent actors closer is an act of location that will require the researcher to be likewise located. Thus, locating transformation also requires reorientation on the part of the researcher. For example, in calling for situated research on climate change impacts, Ensor et al., prompt researchers to ask "what are the most significant changes taking place in people's lives?" (2019). This leads to alternative kinds of enquiry and questioning, such as "how is your life changing?' and 'how do these people experience the world changing?".

The phenomenological understanding of the self as situated in a world and in relations with others implies an acknowledgement of how the self always already is orientated in the world, together with others, and that this such orientation is not a matter of an individual choice. Researchers are also 
implicated in ongoing transformations, with evolving opportunities for learning and development, but we can recognise the demands that incumbent research techniques place on researcher's situations as concerned subjects. Larger societal, historical process shape horizons of meaning, and while there is no determinism here, the self is shaped in and shapes the socio-cultural and historical world it lives. In the light of current climate change, we might say that this change can imply a redirecting and re-orientating of embodied selves, though differently so for differently positioned selves.

We are likewise unavoidably orientated towards transformative change. It directs us in certain, new or novel orientations, whilst we may be orientated in temporal terms both back and forward. In a sense, transformative change can be helpfully understood as a form of cross-scale re-orientation. New signs, frames, metaphors, and meanings are likely to emerge.

Pluralisation

Bringing the two approaches together helps us to dig deeper into the processes of pluralisation. The combined approaches show how transformative changes can be seen as inter-subjective processes; no two peoples experiences will map precisely a particular point on a multi-dimensional spectrum of intentionality and desirability, because everyone experiences a particular change process differently, and makes sense of it and responds to it differently, even where they share in common larger political and physical conditions (Leventon et al., 2021b). When people are located as part of change processes, what may seem 'obvious' and to be 'taken for granted' at a larger scale when employing a systems ontology, becomes more uncertain. This inherent existential condition of existence increases complexity (Mehta and Harcourt, 2021)

We can draw on the notion of transformative experience to understand why different kinds of transformation will be experienced and made sense of in ways that cannot be predicted from the outside. A first-person account will be required: World-changing concerns me. It is my world. Sensemaking analysis demands us to draw from an understanding of dialogism, based on a recognition that though we all experience this world differently, we are co-dependent and co-affected.

Pluralism is an inherent part of the complexity of such processes. It creates certain effects, such as how change processes nevertheless have various faces depending on the inevitably diverse standpoint in the process (instigator, non-instigator etc). The transformation process can be seen as a kind of dialectical momentum between the fixing of certain ideas in shared social forms, and its inherent instability owing to the latent and expressed pluralism.

If perspective shifts are an essential part of sustainability transformations, as suggested by the growing literature on transformative experiences, the preferences that will determine problem descriptions, goals, actions and legitimate actors are bound to change in ways that changes not only interactions within a predefined system, but the entire boundaries and rationale for the assumed systems (Turnhout et al, 2021). 
Transformations literature has been overly skewed by systems thinking and a planetary perspective. Abstract imaginaries like systems and tipping points have led us away from the kinds of transformations that matter to people, and given the neglect of lived experience and meaning in these approaches, cannot account for experiences of transformation. Knowledge for transformation has been prioritised ahead of knowledge about transformation. How people experience transformative change, whether intentional or unintentional, is a key gap in the literature.

Transformation is not an abstract concept or an object, an event or happening that flashes in and out of existence but an ongoing process taking place within people's lives. There is a need to re-trace our steps away from transformations in abstract space, and remember that transformations are always located somewhere, experienced by someone. By drawing on dialogical sense-making and critical phenomenology, transformation studies can usefully complement abstract, large-scale systems-dependent approaches, including political-economy analyses, with attention to the way that people experience and make sense of actually-occurring transformations, and that attend to the structures and content of epistemically and personally transformative experiences. This can help to approach even deliberate transformations with a concern for how they will be experienced and made sense of by people whose lives they will touch, and help us understand how power dimensions and socio-cultural structures can help shape our very ways of experiencing and perceiving actuallyoccurring transformations.

Re-scaling transformation towards first person and dialogical accounts of change may be disorientating, given current attachments to particular techniques of abstract sight and sensemaking concepts. However, attention to such scales makes transformation studies more relevant to people's lives. We have presented an offering of some useful tools we can use to understand that broader set of actually-occurring transformations. By engaging with insights from dialogical sensemaking and critical phenomenology, we show the relevance of experiences and meaning-making to transformation studies. Transformations seen through these lenses are not superficial 'subjective' events, but incorporate the personal, political and practical spheres.

Transformation research that sets out from this combined approach will be concerned with transformation as re-orientations as well as non-linear systems change. It will chart the ways that change processes interact with people's embodied experiences and the ways they make sense of their worlds, and how these are located within power relations that make the change process very different for different people. Transformations are thus comprehended in terms of their lived complexity rather than just complex adaptive systems behaviours. This retelling may open up unimagined channels for transformative change that draw from neglected and plural experiences, knowledges and situated accounts of change.

\section{References:}

Abson, D.J., Fischer, J., Leventon, J. et al. 2017. Leverage points for sustainability transformation. Ambio 46, 30-39.

Armiero, Marco, and Salvatore De Rosa. 'Political Effluvia: Smells, Revelations, and the Politicization of Daily Experience in Naples, Italy', 173-86, 2017. 
Bakhtin, M. M. 1986. Speech Genres and Other Late Essays. Austin: University of Texas Press.

Barry, John. The Politics of Actually Existing Unsustainability: Human Flourishing in a Climate-Changed, Carbon Constrained World. New York: Oxford University Press, USA, 2012.

Beck, Silke, Sheila Jasanoff, Andy Stirling, and Christine Polzin. 'The Governance of Sociotechnical Transformations to Sustainability'. Current Opinion in Environmental Sustainability 49 (April 2021): 143-52. https://doi.org/10.1016/j.cosust.2021.04.010.

Behagel, Jelle Hendrik, and Ayşem Mert. 'The Political Nature of Fantasy and Political Fantasies of Nature'. Journal of Language and Politics 20, no. 1 (21 January 2021): 79-94.

https://doi.org/10.1075/jlp.20049.beh.

Benessaiah, Karina, and Hallie Eakin. 'Crisis, Transformation, and Agency: Why Are People Going Backto-the-Land in Greece?' Sustainability Science 16, no. 6 (November 2021): 1841-58.

https://doi.org/10.1007/s11625-021-01043-5.

Bennett, N. J., Blythe, J., Cisneros-Montemayor, A., Singh, G. G. \& Sumaila, U. R. (2019). Just Transformations to Sustainability, Sustainability, 11(14), 3881.

Berzonsky, Carol L., and Susanne C. Moser. 'Becoming Homo Sapiens: Mapping the Psycho-Cultural Transformation in the Anthropocene'. Anthropocene 20 (December 2017): 15-23.

https://doi.org/10.1016/j.ancene.2017.11.002.

Blythe, J., Silver, J., Evans, L., et al. 2018. The dark side of transformation: latent risks in contemporary sustainability discourse. Antipode, 50, 1206-1223.

Braun, Bruce, and Sarah Whatmore, eds. Political Matter: Technoscience, Democracy, and Public Life. Minneapolis: University of Minnesota Press, 2010.

Cadena, Marisol de la, and Mario Blaser, eds. A World of Many Worlds. Durham: Duke University Press, 2018.

Castree, Noel, William M. Adams, John Barry, Daniel Brockington, Bram Büscher, Esteve Corbera, David Demeritt, et al. 'Changing the Intellectual Climate'. Nature Climate Change 4, no. 9 (September 2014): 763-68. https://doi.org/10.1038/nclimate2339.

Cooke, Benjamin, Simon West, and Wiebren J. Boonstra. 'Dwelling in the Biosphere: Exploring an Embodied Human-Environment Connection in Resilience Thinking'. Sustainability Science 11, no. 5 (September 2016): 831-43. https://doi.org/10.1007/s11625-016-0367-3.

Eakin, Hallie, Rebecca E. Shelton, J. Mario Siqueiros-Garcia, Lakshmi Charli-Joseph, and David ManuelNavarrete. 'Loss and Social-Ecological Transformation: Pathways of Change in Xochimilco, Mexico'. Ecology and Society 24, no. 3 (2019): art15. https://doi.org/10.5751/ES-11030-240315.

Edwards, Paul N. A Vast Machine: Computer Models, Climate Data, and the Politics of Global Warming. Cambridge, Mass.: MIT Press, 2013.

Ensor, Jonathan Edward, Patrick Wennström, Anil Bhatterai, Andrea Joslyn Nightingale, Siri Eriksen, and Jana Sillmann. 'Asking the Right Questions in Adaptation Research and Practice: Seeing beyond Climate Impacts in Rural Nepal'. Environmental Science \& Policy 94 (April 2019): 227-36.

https://doi.org/10.1016/j.envsci.2019.01.013.

Ensor, Jonathan, and Eric Hoddy. 'Securing the Social Foundation: A Rights-Based Approach to Planetary Boundaries'. Earth System Governance 7 (March 2021): 100086.

https://doi.org/10.1016/j.esg.2020.100086.

Eriksen, Siri H., Andrea J. Nightingale, and Hallie Eakin. 'Reframing Adaptation: The Political Nature of Climate Change Adaptation'. Global Environmental Change 35 (November 2015): 523-33.

https://doi.org/10.1016/j.gloenvcha.2015.09.014. 
Fazey, Ioan, Niko Schäpke, Guido Caniglia, Anthony Hodgson, Ian Kendrick, Christopher Lyon, Glenn Page, et al. 'Transforming Knowledge Systems for Life on Earth: Visions of Future Systems and How to Get There'. Energy Research \& Social Science 70 (December 2020): 101724.

https://doi.org/10.1016/j.erss.2020.101724.

Feola, G. 2015. Societal transformation in response to global environmental change: a review of emerging concepts. Ambio, 44, 376-390.

Folke, Carl, Stephen Polasky, Johan Rockström, Victor Galaz, Frances Westley, Michèle Lamont, Marten Scheffer, et al. 'Our Future in the Anthropocene Biosphere'. Ambio 50, no. 4 (April 2021): 834-69. https://doi.org/10.1007/s13280-021-01544-8.

Forsyth, Tim. 'Time to Change? Technologies of Futuring and Transformative Change in Nepal's Climate Change Policy'. Globalizations 18, no. 6 (18 August 2021): 966-80.

https://doi.org/10.1080/14747731.2020.1859766.

Gelves-Gómez, Francisco, and Shannon Brincat. 'Leveraging Vanua: Metaphysics, Nature, and Climate Change Adaptation in Fiji'. In Beyond Belief, edited by Johannes M. Luetz and Patrick D. Nunn, 59-79. Climate Change Management. Cham: Springer International Publishing, 2021. https://doi.org/10.1007/978-3-030-67602-5 4.

Giddens, A. (1984). The Constitution of Society: Outline of the Theory of Structuration. Cambridge, UK, Policy Press.

Habu and Yeo, 2021. Untold stories of climate change loss and damage in the LDCs: Solomon Islands. Animated Video. Available at: https://youtu.be/8IA4e-1Aiu0. (Accessed 20/10/2021)

Habu, G., 2021. Engulfed by the sea: the loss and damage from climate change. Available at: https://www.iied.org/engulfed-sea-loss-damage-climate-change (Accessed 20/10/2021)

Hajer, Maarten and Frank Fischer, "Beyond Global Discourse: The Rediscovery of Culture in Environmental Politics". In Hajer, M. and Fischer, F. (eds.). Living With Nature: Environmental Politics as Cultural Discourse. Oxford UP, Oxford, 1999;

Hajer, Maarten, Måns Nilsson, Kate Raworth, Peter Bakker, Frans Berkhout, Yvo de Boer, Johan Rockström, Kathrin Ludwig, and Marcel Kok. 'Beyond Cockpit-Ism: Four Insights to Enhance the Transformative Potential of the Sustainable Development Goals'. Sustainability 7, no. 2 (4 February 2015): 1651-60. https://doi.org/10.3390/su7021651.

Haraway, Donna. 'Situated Knowledges: The Science Question in Feminism and the Privilege of Partial Perspective'. Feminist Studies 14, no. 3 (1988): 575. https://doi.org/10.2307/3178066.

Haverkamp, Jamie. 'Collaborative Survival and the Politics of Livability: Towards Adaptation Otherwise'. World Development 137 (January 2021): 105152.

https://doi.org/10.1016/j.worlddev.2020.105152.

Herrfahrdt-Pähle, Elke, Maja Schlüter, Per Olsson, Carl Folke, Stefan Gelcich, and Claudia Pahl-Wostl. 'Sustainability Transformations: Socio-Political Shocks as Opportunities for Governance Transitions'. Global Environmental Change 63 (July 2020): 102097. https://doi.org/10.1016/j.gloenvcha.2020.102097.

Hoque, Sonia Ferdous, Claire Quinn, and Susannah Sallu. 'Differential Livelihood Adaptation to SocialEcological Change in Coastal Bangladesh'. Regional Environmental Change 18, no. 2 (February 2018): 451-63. https://doi.org/10.1007/s10113-017-1213-6. 
IIED; 2021, Brutal realities of climate change loss and damage come to life in IIED animations. . Available at: https://www.iied.org/brutal-realities-climate-change-loss-damage-come-life-iiedanimations (Accessed 20/10/2021)

Jackson, Guy. 'Perceptions of Disaster Temporalities in Two Indigenous Societies from the Southwest Pacific'. International Journal of Disaster Risk Reduction 57 (April 2021): 102221.

https://doi.org/10.1016/j.ijdrr.2021.102221.

Jasanoff, Sheila. 'A New Climate for Society'. Theory, Culture \& Society 27, no. 2-3 (March 2010): 23353. https://doi.org/10.1177/0263276409361497.

Johansson, Anna, and Stellan Vinthagen. 'Dimensions of Everyday Resistance: An Analytical

Framework'. Critical Sociology 42, no. 3 (May 2016): 417-35.

https://doi.org/10.1177/0896920514524604.

Jones, Lucile M. The Big Ones: How Natural Disasters Have Shaped Us (and What We Can Do about Them). First edition. New York: Doubleday, 2018.

Kaijser, Anna, and Annica Kronsell. 'Climate Change through the Lens of Intersectionality'. Environmental Politics 23, no. 3 (4 May 2014): 417-33.

https://doi.org/10.1080/09644016.2013.835203.

Lahsen, Myanna, and Esther Turnhout. 'How Norms, Needs, and Power in Science Obstruct Transformations towards Sustainability'. Environmental Research Letters 16, no. 2 (1 February 2021): 025008. https://doi.org/10.1088/1748-9326/abdcfo.

Latour, Bruno. Down to Earth: Politics in the New Climatic Regime. English edition. Cambridge, UK ; Medford, MA: Polity, 2018.

Leventon, Julia, Dave J. Abson, and Daniel J. Lang. 2021a Leverage Points for Sustainability Transformations: Nine Guiding Questions for Sustainability Science and Practice'. Sustainability Science 16, no. 3 (May 2021): 721-26. https://doi.org/10.1007/s11625-021-00961-8.

Leventon, Julia, Ioana A. Duşe, and Andra-Ioana Horcea-Milcu 2021b. Leveraging Biodiversity Action From Plural Values: Transformations of Governance Systems. Frontiers in Ecology and Evolution 9 (4 June 2021): 609853. https://doi.org/10.3389/fevo.2021.609853.

Linell, P. 2009. Rethinking Language, Mind, and World Dialogically: Interactional and Contextual Theories of Human Sense Making. Charlotte, NC: Information Age Publishing.

Linnér, B-O (2003). The Return of Malthus: Environmentalism and Postwar Population-Resource Crises. Cambridge, UK. White Horse Press. Second revised edition forthcoming 2022.

Linnér B.-O., Wibeck V. 2019. Sustainability transformations: agents and drivers across societies. Cambridge University Press, Cambridge.

Lippuner, R. and B. Werlen (2009). Structuration theory. International Encyclopedia of Human Geography. R. Kitchin and N. Thrift. Amsterdam, NL, Elsevier: 35-49.

Malmqvist, E., Zeiler, K. 2010. Cultural Norms, the Phenomenology of Incorporation and the Experience of Having a Child Born with Ambiguous Sex. Social Theory and Practice 36(1): $157-164$.

Manuel-Navarrete, David, and Mark Pelling. 'Subjectivity and the Politics of Transformation in Response to Development and Environmental Change'. Global Environmental Change 35 (November 2015): 558-69. https://doi.org/10.1016/j.gloenvcha.2015.08.012.

Marková, I., Linell, P., Grossen, M. \& Salazar Orvig, A. 2007. Dialogue in Focus Groups: Exploring in Socially Shared Knowledge. London: Equinox Publishing.

Massarella, Kate, Anja Nygren, Robert Fletcher, Bram Büscher, Wilhelm A Kiwango, Sanna Komi, Judith E Krauss, et al. 'Transformation beyond Conservation: How Critical Social Science Can 
Contribute to a Radical New Agenda in Biodiversity Conservation'. Current Opinion in Environmental Sustainability 49 (April 2021): 79-87. https://doi.org/10.1016/j.cosust.2021.03.005.

Mauser, W., Klepper, G., Rice, M., et al. 2013. Transdisciplinary global change research: the co-creation of knowledge for sustainability. Current Opinion in Environmental Sustainability, 5, 420-431.

McHugh, Lucy Holmes, Maria Carmen Lemos, and Tiffany Hope Morrison. 'Risk? Crisis? Emergency? Implications of the New Climate Emergency Framing for Governance and Policy'. WIREs Climate Change 12, no. 6 (November 2021). https://doi.org/10.1002/wcc.736.

Meadows D.H. 2008. Thinking in systems: a primer. Chelsea Green Publishing Company, White River Junction.

Mehleb, Rimel I., Giorgos Kallis, and Christos Zografos. 'A Discourse Analysis of Yellow-Vest Resistance against Carbon Taxes'. Environmental Innovation and Societal Transitions 40 (September 2021): 38294. https://doi.org/10.1016/j.eist.2021.08.005.

Mehta, Lyla, and Wendy Harcourt. 'Beyond Limits and Scarcity: Feminist and Decolonial Contributions to Degrowth'. Political Geography 89 (August 2021): 102411.

https://doi.org/10.1016/j.polgeo.2021.102411.

Mehta, Lyla, Shilpi Srivastava, Synne Movik, Hans Nicolai Adam, Rohan D’Souza, Devanathan Parthasarathy, Lars Otto Naess, and Nobuhito Ohte. 'Transformation as Praxis: Responding to Climate Change Uncertainties in Marginal Environments in South Asia'. Current Opinion in Environmental Sustainability 49 (April 2021): 110-17. https://doi.org/10.1016/j.cosust.2021.04.002.

Milkoreit, M. 2017. Imaginary politics: Climate change and making the future. Elementa: Science of the Anthropocene, 5: 62.

Moore, Brendan, Caroline Verfuerth, Angela Mae Minas, Christianne Tipping, Sarah Mander, Irene Lorenzoni, Claire Hoolohan, Andrew J. Jordan, and Lorraine Whitmarsh. 'Transformations for Climate Change Mitigation: A Systematic Review of Terminology, Concepts, and Characteristics'. WIRES Climate Change 12, no. 6 (November 2021). https://doi.org/10.1002/wcc.738.

Moriggi, Angela, Katriina Soini, Alex Franklin, and Dirk Roep. 'A Care-Based Approach to Transformative Change: Ethically-Informed Practices, Relational Response-Ability \& Emotional Awareness'. Ethics, Policy \& Environment 23, no. 3 (1 September 2020): 281-98.

https://doi.org/10.1080/21550085.2020.1848186.

Morton, Timothy. Hyperobjects: Philosophy and Ecology after the End of the World. Posthumanities 27. Minneapolis: University of Minnesota Press, 2013.

Moser, Susanne C. 'The Work after "It's Too Late" (to Prevent Dangerous Climate Change)'. WIRES Climate Change 11, no. 1 (January 2020). https://doi.org/10.1002/wcc.606.

Nicholas, Kimberly. Under the Sky We Make: How to Be Human in a Warming World. New York: G.P. Putnam's Sons, 2021.

Nightingale, Andrea J. 'Power and Politics in Climate Change Adaptation Efforts: Struggles over Authority and Recognition in the Context of Political Instability'. Geoforum 84 (August 2017): 11-20. https://doi.org/10.1016/j.geoforum.2017.05.011.

Nightingale, Andrea J., Noémi Gonda, and Siri H. Eriksen. 'Affective Adaptation = Effective Transformation? Shifting the Politics of Climate Change Adaptation and Transformation from the Status Quo'. WIREs Climate Change, 18 October 2021. https://doi.org/10.1002/wcc.740.

Nightingale, Andrea Joslyn, Siri Eriksen, Marcus Taylor, Timothy Forsyth, Mark Pelling, Andrew Newsham, Emily Boyd, et al. 'Beyond Technical Fixes: Climate Solutions and the Great Derangement'. Climate and Development 12, no. 4 (20 April 2020): 343-52.

https://doi.org/10.1080/17565529.2019.1624495. 
O'Brien K, El Khoury A, Schafenacker N, Rosenfeld J (eds). 2019. Our entangled future: stories to empower quantum social change. Adaptation CONNECTS research project. University of Oslo, Oslo

O'Brien, K. \& Sygna, L. 2013. Responding to climate change: the three spheres of transformation. Proceedings of Transformation in a Changing Climate. Oslo: University of Oslo.

O'Brien, K. 2018. Is the $1.5^{\circ} \mathrm{C}$ target possible? Exploring the three spheres of transformation. Current Opinion in Environmental Sustainability, 31, 153-160.

O’Brien, Karen. You Matter More than You Think: Quantum Social Change for a Thriving World, 2021.

Pathways Network (Project), ed. Transformative Pathways to Sustainability: Learning across Disciplines, Cultures and Contexts. Pathways to Sustainability. Abingdon, Oxon ; New York, NY: Routledge, 2022.

Patterson, J., Schulz, K., Vervoort, J., et al. 2017. Exploring the governance and politics of transformations towards sustainability. Environmental Innovation and Societal Transitions, 24, 1-16.

Patterson, James, Carina Wyborn, Linda Westman, Marie Claire Brisbois, Manjana Milkoreit, and Dhanasree Jayaram. 'The Political Effects of Emergency Frames in Sustainability'. Nature Sustainability 4, no. 10 (October 2021): 841-50. https://doi.org/10.1038/s41893-021-00749-9.

Pelling, Mark, Karen O’Brien, and David Matyas. 'Adaptation and Transformation'. Climatic Change 133, no. 1 (November 2015): 113-27. https://doi.org/10.1007/s10584-014-1303-0.

Pereira, L., Frantzeskaki, N., Hebinck, A., Charli-Joseph, L., Drimie, S., Dyer, M., Eakin, H., Galafassi, D., Karpouzoglou, T., Marshall, F., Moore, M.-L., Olsson, P., Siqueiros-Garcia, J. M., van Zwanenberg, P., and Vervoort, J.M. (2020). Transformative spaces in the making: key lessons from nine cases in the Global South. Sustainability Science 15:161-178

Pettit, P. (1993). The common mind : an essay on psychology, society, and politics. New York, Oxford University Press.

Priebe, Janina, Erland Mårald, and Annika Nordin. 'Narrow Pasts and Futures: How Frames of Sustainability Transformation Limit Societal Change'. Journal of Environmental Studies and Sciences 11, no. 1 (March 2021): 76-84. https://doi.org/10.1007/s13412-020-00636-3.

Quealy, Harry M., and Julian S. Yates. 'Situated Adaptation: Tackling the Production of Vulnerability through Transformative Action in Sri Lanka's Dry Zone'. Global Environmental Change 71 (November 2021): 102374. https://doi.org/10.1016/j.gloenvcha.2021.102374.

Ramachandra Guha and Juan Martinez-Alier, Varieties of Environmentalism: Essays North and South, Earthscan, London;

Riedy, C. 2021. Discursive entrepreneurship: ethical meaning-making as a transformative practice for sustainable futures. Sustainability Science. https://doi.org/10.1007/s11625-021-00978-z

Schipper, E. Lisa F., Navroz K. Dubash, and Yacob Mulugetta. 'Climate Change Research and the Search for Solutions: Rethinking Interdisciplinarity'. Climatic Change 168, no. 3-4 (October 2021): 18. https://doi.org/10.1007/s10584-021-03237-3.

Schipper, E.L.F., S.E. Eriksen, L.R. Fernandez Carril, B.C. Glavovic, and Z. Shawoo. 'Turbulent Transformation: Abrupt Societal Disruption and Climate Resilient Development'. Climate and Development 13, no. 6 (3 July 2021): 467-74. https://doi.org/10.1080/17565529.2020.1799738.

Scoones, Ian, Melissa Leach, and Peter Newell, eds. The Politics of Green Transformations. Pathways to Sustainability. London; New York: Routledge, 2015.

Shove, Elizabeth. 'Beyond the ABC: Climate Change Policy and Theories of Social Change'. Environment and Planning A: Economy and Space 42, no. 6 (June 2010): 1273-85.

https://doi.org/10.1068/a42282. 
Stålhammar, Sanna. 'Assessing People's Values of Nature: Where Is the Link to Sustainability Transformations?' Frontiers in Ecology and Evolution 9 (19 March 2021): 624084.

https://doi.org/10.3389/fevo.2021.624084.

Stripple, Johannes, Alexandra Nikoleris, and Roger Hildingsson. 'Carbon Ruins: Engaging with PostFossil Transitions through Participatory World-Building'. Politics and Governance 9, no. 2 (28 April 2021): 87-99. https://doi.org/10.17645/pag.v9i2.3816.

Stripple, Johannes, and Harriet Bulkeley. 'Towards a Material Politics of Socio-Technical Transitions: Navigating Decarbonisation Pathways in Malmö’. Political Geography 72 (June 2019): 52-63. https://doi.org/10.1016/j.polgeo.2019.04.001.

Tsing, Anna Lowenhaupt, ed. Arts of Living on a Damaged Planet. Minneapolis: University of Minnesota Press, 2017.

Turnhout, Esther, Tamara Metze, Carina Wyborn, Nicole Klenk, and Elena Louder. 'The Politics of CoProduction: Participation, Power, and Transformation'. Current Opinion in Environmental Sustainability 42 (February 2020): 15-21. https://doi.org/10.1016/j.cosust.2019.11.009.

Uhrqvist, Ola, Lisa Carlsson, Ann-Sofie Kall, and Therese Asplund. 'Sustainability Stories to Encounter Competences for Sustainability'. Journal of Education for Sustainable Development 15, no. 1 (March 2021): 146-60. https://doi.org/10.1177/09734082211005041.

Vaioleti TM (2006) Talanoa Research Methodology: A developing position on Pacific research. Waikato Journal of Education 12: 21-34.

Veland S, Scoville-Simonds M, Gram-Hanssen I et al (2019) Narrative matters for sustainability: the transformative role of storytelling in realizing $1.5{ }^{\circ} \mathrm{C}$ futures. Current Opinion in Environmental Sustainability, 31:41-47

Wamsler, Christine, Gustav Osberg, Walter Osika, Heidi Herndersson, and Luis Mundaca. 'Linking Internal and External Transformation for Sustainability and Climate Action: Towards a New Research and Policy Agenda'. Global Environmental Change 71 (November 2021): 102373.

https://doi.org/10.1016/j.gloenvcha.2021.102373.

WBGU. 2011. World in Transition: A Social Contract for Sustainability. Flagship Report. Berlin: German Advisory Council on Global Change.

Wendt, A. (2015). Quantum mind and social science : unifying physical and social ontology. Cambridge, UK, Cambridge University Press.

West, Simon, L. Jamila Haider, Sanna Stålhammar, and Stephen Woroniecki. 'A Relational Turn for Sustainability Science? Relational Thinking, Leverage Points and Transformations'. Ecosystems and People 16, no. 1 (1 January 2020): 304-25. https://doi.org/10.1080/26395916.2020.1814417.

Westley, Frances R., Ola Tjornbo, Lisen Schultz, Per Olsson, Carl Folke, Beatrice Crona, and Örjan Bodin. 'A Theory of Transformative Agency in Linked Social-Ecological Systems'. Ecology and Society 18, no. 3 (2013): art27. https://doi.org/10.5751/ES-05072-180327.

Wibeck, V., Linnér, B.-O. 2021. Sense-making analysis: a framework for multi-strategy and crosscountry research. International Journal of Qualitative Methods 20:1-20

Wibeck, V., Eliasson, K., and Neset, T.-S. (2022). Co-creation research for transformative times: Facilitating foresight capacity in view of global sustainability challenges. Environmental Science \& Policy. 128 (February 2022) 290-298

Zeiler, K., and Käll, L. Folkmarson (eds). Feminist Phenomenology and Medicine. State University of New York Press (SUNY Press), 2014. 
Zeiler, K., De Boer, M. 2020. The Empirical and the Philosophical in Empirical Bioethics: Time for a Conceptual Turn. AJOB Empirical Bioethics, Vol. 11, s. 11-13 (First Publ. 25 Feb 2020). 